\title{
Overtreatment in nonmalignant lesions detected in a colorectal cancer screening program: a retrospective cohort study
}

Joaquín Cubiella $a^{1,2,3^{*}}$ D , Antía González ${ }^{4}$, Raquel Almazán ${ }^{5}$, Elena Rodríguez-Camacho ${ }^{5}$, Raquel Zubizarreta ${ }^{5}$ and Isabel Peña-Rey Lorenzo ${ }^{5}$

\begin{abstract}
Background: Although colorectal cancer (CRC) screening programs reduce CRC incidence and mortality, they are associated with risks in healthy subjects. However, the risk of overtreatment and overdiagnosis has not been determined yet. The aim of this study was to report the surgery rates in patients with nonmalignant lesions detected within the first round of a fecal immunochemical test (FIT) based CRC screening program and the factors associated with it.

Methods: We included in this analysis all patients with nonmalignant lesions detected between May 2013 and June 2019 in the Galician (Spain) CRC screening program. We calculated surgery rate according to demographic variables, the risk classification according to the colonoscopy findings (European guidelines for quality assurance), the endoscopist's adenoma detection rate (ADR) classified into quartiles and the hospital's complexity level. We determined which variables were independently associated with surgery rate and expressed the association as Odds Ratio and its 95\% confidence interval (Cl).

Results: We included 15,707 patients in the analysis with high (19.9\%), intermediate (26.9\%) low risk (23.3\%) adenomas and normal colonoscopy (29.9\%) detected in the analyzed period. Colorectal surgery was performed in 162 patients $(1.03,95 \% \mathrm{Cl} 0.87-1.19)$, due to colonoscopy complications $(0.02,95 \% \mathrm{Cl} 0.00-0.05)$ and resection of colorectal benign lesions $(1.00,95 \% \mathrm{Cl} 0.85-1.16)$. Median hospital stay was 6 days with $17.3 \%$ patients developing minor complications, $7.4 \%$ major complications and one death. After discharge, complications developed in 18.4\% patients. In benign lesions, an endoscopic resection was performed in $25.4 \%$ and a residual premalignant lesion was detected in $89.9 \%$. The variables independently associated with surgery in the multivariable analysis were age ( $\geq 60$ years $=1.57,95 \% \mathrm{Cl} 1.11-2.23$ ), sex (female $=2.10,95 \% \mathrm{Cl} 1.52-2.91$ ), the European guidelines classification (high risk $=67.94,95 \% \mathrm{Cl} 24.87-185.59$; intermediate risk $=5.63$, 95\% Cl 1.89-16.80; low risk $=1.43 ; 95 \% \mathrm{Cl} 0.36-5.75)$, the endoscopist's ADR (Q4 = 0.44, 95\% Cl 0.28-0.68; Q3 = 0.44, 95\% Cl 0.27-0.71; Q2 =0.71, 95\% Cl 0.44-1.14) and the hospital (tertiary $=0.54,95 \% \mathrm{Cl} 0.38-0.79$ ).
\end{abstract}

\footnotetext{
* Correspondence: joaquin.cubiella.fernandez@sergas.es

${ }^{1}$ Department of Gastroenterology, Hospital Universitario de Ourense, Rúa

Ramón Puga 52-56, 32003 Ourense, Spain

${ }^{2}$ Instituto de Investigación Sanitaria Galicia Sur, Ourense, Spain

Full list of author information is available at the end of the article
}

C C The Author(s). 2021 Open Access This article is licensed under a Creative Commons Attribution 4.0 International License, which permits use, sharing, adaptation, distribution and reproduction in any medium or format, as long as you give appropriate credit to the original author(s) and the source, provide a link to the Creative Commons licence, and indicate if changes were made. The images or other third party material in this article are included in the article's Creative Commons licence, unless indicated otherwise in a credit line to the material. If material is not included in the article's Creative Commons licence and your intended use is not permitted by statutory regulation or exceeds the permitted use, you will need to obtain permission directly from the copyright holder. To view a copy of this licence, visit http://creativecommons.org/licenses/by/4.0/ The Creative Commons Public Domain Dedication waiver (http://creativecommons.org/publicdomain/zero/1.0/) applies to the data made available in this article, unless otherwise stated in a credit line to the data. 
Conclusions: In a CRC screening program, the surgery rate and the associated complications in patients with nonmalignant lesions are low, and related to age, sex, endoscopic findings, endoscopist's ADR and the hospital's complexity.

Keywords: Adenoma detection rate, Colorectal cancer, Overtreatment, Screening, Surgical resection

\section{Background}

Colorectal cancer (CRC) is the second most frequent cancer worldwide with almost two million incident cases and one million related deaths in 2020 [1]. In order to reduce the disease burden, population-based CRC screening programs have been established in the Western world. This strategy has demonstrated their efficacy to reduce CRC mortality and incidence in randomized controlled trials [2]. Furthermore, CRC screening programs have demonstrated their efficiency in reducing both CRC mortality and incidence $[3,4]$.

Screening programs are directed to asymptomatic subjects. A key point o is the minimization of risks. The benefit gained by individuals should outweigh any harm [5]. Although complications related to the diagnostic tests are well established in CRC screening $[2,6]$, there is no such certainty regarding overdiagnosis and overtreatment. Overdiagnosis is defined as the diagnosis of a medical condition or disease that would not cause symptoms or death during a patient's lifetime. In the case of CRC screening, treatment of overdiagnosed CRC and polyps should be called overtreatment [7].

Endoscopic resection of colorectal polyps is the key to reduce CRC incidence and mortality [8]. Although side effects are limited, mainly postpolypectomy syndrome, rectal bleeding and perforation, they account for most colonoscopy-related injury during CRC screening [2]. Endoscopic resection removes up to $90 \%$ of advanced complex polyps [9]. However, the introduction of CRC screening programs has increased the number of colectomies due to benign polyps. In the US, up to $25 \%$ of colectomies were performed for non-malignant polyps [10]. Related mortality and morbidity attains 0.8 and $25.3 \%$, respectively [11]. However, there is little information regarding the incidence of surgery and associated risks in subjects with benign lesions detected in a CRC screening program [12] Thus, we decided to perform a retrospective cohort analysis in the first round of the Galician (northwestern Spain) CRC screening program to determine the surgery rate in patients with non-malignant lesions detected on colonoscopy, the surgery-related complications, the motivation for surgery and finally, the factors independently associated with it.

\section{Methods}

\section{Study design}

We designed a retrospective cohort multicenter study using the Galician (Northwestern Spain) CRC screening program database to identify patients. We included in this analysis all patients that underwent at least one colonoscopy in the first round of the CRC screening program from its implementation (May 2013) until July 2019. We excluded patients with an invasive CRC as the final diagnosis.

\section{Description of the Galician CRC screening program}

Galician CRC mass screening and its implementation have been described elsewhere [13]. The CRC screening program includes the central coordination and management of patient follow-up after polyp resection depending on their risk according to EU guidelines for quality assurance on CRC screening recommendations [14]. The Coordination Unit personnel introduces the data obtained from the different sources in the screening program information system regarding CRC stage according to the AJCC classification [15], the final classification of patients with a positive result [14] as well as several quality endoscopist indicators according to Spanish guidelines on quality in screening colonoscopy [16].

\section{Baseline data}

From each patient, we collected the information available in the screening program database: sex, age, fecal hemoglobin concentration, performance status, associated medical illnesses graded according to the American Society of Anesthesiologists' Physical Status Classification (ASA grade), number of baseline colonoscopies (colonoscopies performed after the positive FIT result), number of polyps, adenomas and size of the largest adenoma. Patients were classified as high risk $(\geq 20 \mathrm{~mm}$ or $\geq 5$ adenomas), intermediate risk ( 3 to 4 adenomas, $1 \geq 10 \mathrm{~mm}$ and $<20 \mathrm{~mm}$, with a villous component or high grade dysplasia), low risk (1-2 tubular adenomas < $10 \mathrm{~mm}$ in size) and no adenomas according to the European guidelines for quality assurance in CRC screening [17]. Data regarding the center and the endoscopist that performed the first complete colonoscopy were collected. The adenoma detection rate (ADR) and number of colonoscopies performed during the first round were calculated for each endoscopist in the first round. Endoscopists were classified into quartiles according to 
their ADR and number of colonoscopies performed. Finally, hospitals were classified according to their complexity level (tertiary versus secondary).

\section{Surgery}

We identified all the patients that required surgery after colonoscopy using the Spanish Health System's Hospital Discharge Records Database (CMBD in Spanish) and the CRC screening program database. The CMBD includes information on hospital discharges using a list of clinical codes to establish the diagnosis that justified the admission The CMBD database receives notifications from approximately $98 \%$ of Spanish public hospitals [18]. Mandatory health insurance covers an estimated 99.5\% of the Spanish population, although subjects not covered by health insurance can still receive treatment in public hospitals. All subjects included in the Galician CRC screening programme are attended in the Galician Public health System. The International classification of diseases (ICD) codes used to identify colorectal surgeries were: ICD-9-MC 48.6 over the period 2013-2015 and ICD-10-ES ODT(C,E-N,P) $(0,4) \quad Z Z ; O D B(C, E-N, P)(0,4)$ ZZ and ODBP7ZZ over the period 2016-2019. We subsequently searched manually the clinical records of identified patients to confirm that colorectal surgery was related to the screening colonoscopy. Moreover, we retrieved the following data: reason for surgery, type of surgery, length of hospital stay and complications either during hospitalization or after discharge (first year). We searched the clinical information in IANUS, the Galician electronic health record system that covers both all the Galician hospitals and the primary healthcare centers. Inhospital complications were classified according to the Clavien-Dindo classification [19]. We classified surgery complications as minor if they were grade I-II and major if they were grade III-V. If surgery was due to resection of colorectal lesions, we collected data regarding size, morphology according to the Paris classification [20], location, endoscopic resection and histologic findings in the endoscopic and surgical specimen. Based on endoscopic reports we calculated the Size, Morphology, Site and Access (SMSA) score and we classified lesions accordingly [21].

\section{Analysis}

First, we described the characteristics of the subjects included. We reported continuous and categorical variables as median and interquartile range (IQR), and total number and percentage, respectively. Thereafter, we calculated the surgery rate according to the different variables assessed. We performed a bivariate analysis using the Chi-square test for categorical variables and the Student's $t$ test for continuous variables to determine those related to surgery. Finally, we included statistically significant or clinically relevant variables in a multivariable analysis using logistic regression (forward conditional) to determine which variables were independently related to surgery. We performed a secondary analysis after excluding transanal surgery to determine the colectomy rate, related complications and independently associated factors. Associations were expressed as Odds Ratio (OR) with a 95\% confidence interval (CI). Statistical analyses were performed with IBM SPSS Statistics for Windows, Version 22.0. Armonk, NY, USA: IBM Corp.

\section{Ethics issues}

The local Institutional Review Board assessed and approved the study (code 2018/593). As long as the study was based on database operation, no informed consent was required. The information was accessed according to prevailing European and Spanish legislation.

\section{Results}

\section{Description of the sample}

Between May 2013 and June 2019, a total of 16,720 subjects underwent at least one colonoscopy during the first round of the Galician CRC screening program. We excluded 1013 subjects with CRC as the final diagnosis from this analysis. Therefore, we included in the analysis 15,707 patients without a CRC in the first round. After linking this data with the CMBD database, we identified 352 patients with any of the codes related to colorectal surgery. After verifying the clinical records, we confirmed that 162 underwent colorectal surgery related to participation in the screening program, four due to colonoscopy-related complications and 158 due to resection of colorectal lesions (Fig. 1 and Table 1). The surgery rate was as follows: global: 1.03\% (95\% CI $0.87-$

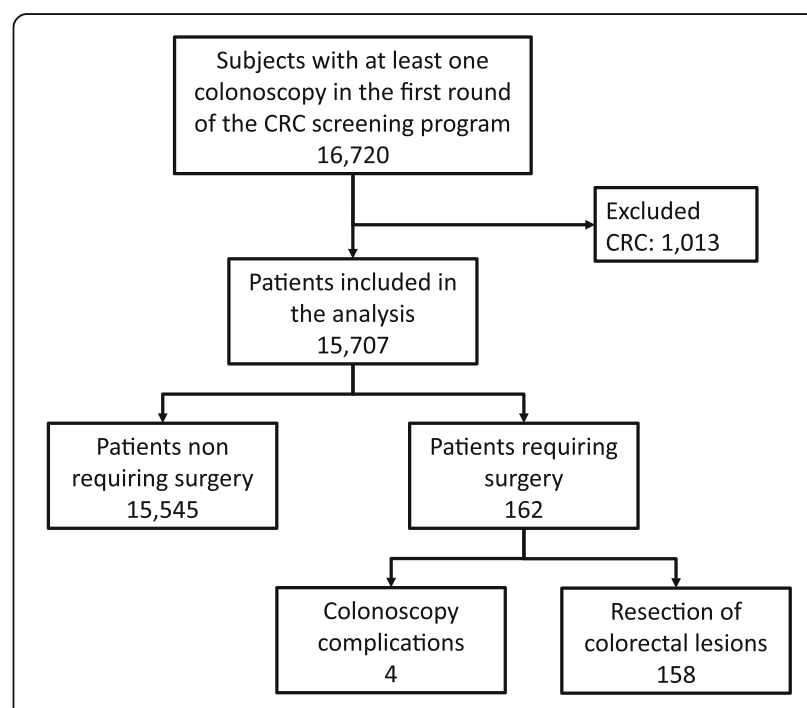

Fig. 1 Flowchart of patients included in the analysis 
Table 1 Baseline characteristics and surgery rate according to dependent variables

\begin{tabular}{|c|c|c|c|c|c|}
\hline & & $\begin{array}{l}\text { Patients not requiring surgery } \\
(n=15,545)\end{array}$ & $\begin{array}{l}\text { Surgery } \\
(n=162)\end{array}$ & $\begin{array}{l}\text { Surgery rate \% }(95 \% \\
\mathrm{Cl})\end{array}$ & Significance $^{\mathrm{a}}$ \\
\hline \multirow[t]{2}{*}{$\operatorname{Sex}(n=15,707)$} & - Female & $6708(43.2 \%)$ & $72(44.4 \%)$ & $1.06(0.82-1.31)$ & \multirow[t]{2}{*}{0.7} \\
\hline & - Male & $8837(56.8 \%)$ & $90(55.6 \%)$ & $1.01(0.80-1.22)$ & \\
\hline \multirow[t]{2}{*}{ Age $(n=15,707)$} & $\cdot<60$ years & $6855(44.1 \%)$ & $48(29.6 \%)$ & $0.69(0.50-0.89)$ & \multirow[t]{2}{*}{$<0.001$} \\
\hline & $\cdot \geq 60$ years & $8690(55.9 \%)$ & $114(70.4 \%)$ & $1.29(1.06-1.53)$ & \\
\hline \multirow[t]{2}{*}{ PS $(n=15,383)$} & $\cdot 0$ & $12,388(81.3 \%)$ & $132(83.0 \%)$ & $1.05(0.87-1.23)$ & \multirow[t]{2}{*}{0.8} \\
\hline & $\cdot 1$ & $2836(18.6 \%)$ & $27(17.0 \%)$ & $0.94(0.59-1.29)$ & \\
\hline \multirow[t]{3}{*}{ ASA $(n=15,383)$} & $\cdot 1$ & $8876(58.2 \%)$ & $96(60.3 \%)$ & $1.07(0.86-1.28)$ & \multirow[t]{3}{*}{0.9} \\
\hline & $\cdot \|$ & $5391(35.4 \%)$ & $53(33.3 \%)$ & $0.97(0.71-1.23)$ & \\
\hline & $\cdot|| \mid$ & $957(6.3 \%)$ & $10(6.3 \%)$ & $1.03(0.40-1.67)$ & \\
\hline \multirow[t]{3}{*}{ Fecal Hb $(n=15,707)$} & $\cdot<100 \mu \mathrm{g} / \mathrm{g}$ & $10,388(66.8 \%)$ & 79 (48.8\%) & $0.75(0.59-0.92)$ & \multirow[t]{3}{*}{$<0.001$} \\
\hline & 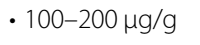 & $2935(18.9 \%)$ & $41(25.3 \%)$ & $1.42(0.99-1.86)$ & \\
\hline & $\cdot>200 \mu \mathrm{g} / \mathrm{g}$ & $2222(14.3 \%)$ & $42(25.9 \%)$ & $1.85(1.30-2.41)$ & \\
\hline \multirow[t]{2}{*}{ N.colonoscopies $(n=15,707)$} & - One & $13,557(87.2 \%)$ & $122(75.3 \%)$ & $0.89(0.73-1.05)$ & \multirow[t]{2}{*}{$<0.001$} \\
\hline & - At least two & $1988(12.8 \%)$ & $40(24.7 \%)$ & $1.97(1.37-2.58)$ & \\
\hline Number of polyps $(n=15,707)$ & & $2(\mathrm{IQR} 1-4)$ & $3(\mathrm{QQR} 1-5)$ & & $<0.001$ \\
\hline Number of adenomas $(n=15,707)$ & & $1(\mathrm{QQR} 0-3)$ & $2(\mathrm{IQR} 1-4)$ & & $<0.001$ \\
\hline Adenoma size $(\mathrm{mm})(n=15,707)$ & & $5(\mathrm{IQR} 0-12)$ & $\begin{array}{l}19(\mathrm{IQR} 8- \\
31.3)\end{array}$ & & $<0.001$ \\
\hline \multirow{4}{*}{$\begin{array}{l}\text { European guidelines classification } \\
(n=15,707)\end{array}$} & - No adenoma & $4650(29.9 \%)$ & $4(2.5 \%)$ & $0.08(0.00-0.17)$ & \multirow[t]{4}{*}{$<0.001$} \\
\hline & - Low risk & $3626(23.3 \%)$ & $4(2.5 \%)$ & $0.11(0.00-0.22)$ & \\
\hline & $\begin{array}{l}\text { - Intermediate } \\
\text { risk }\end{array}$ & 4179 (26.9\%) & $17(10.5 \%)$ & $0.40(0.21-0.59)$ & \\
\hline & • High risk & $3090(19.9 \%)$ & $137(84.6 \%)$ & $4.24(3.55-4.94)$ & \\
\hline \multirow[t]{4}{*}{ Endoscopist's ADR $(n=15,459)$} & $\cdot$ - Q1 ( $\leq 60 \%)$ & $2653(17.3 \%)$ & $42(26.1 \%)$ & $1.56(1.09-2.03)$ & \multirow[t]{4}{*}{0.02} \\
\hline & • Q2 (60-65.3\%) & $3989(26.1 \%)$ & $40(24.8 \%)$ & $0.99(0.67-1.30)$ & \\
\hline & $\begin{array}{l}\cdot \text { Q3 (65.3- } \\
\text { 70.8\%) }\end{array}$ & $4181(27.3 \%)$ & $34(21.1 \%)$ & $0.81(0.54-1.08)$ & \\
\hline & • Q4 (> 70.8\%) & $4474(29.2 \%)$ & $45(28.0 \%)$ & $0.99(0.71-1.28)$ & \\
\hline \multirow{4}{*}{$\begin{array}{l}\text { Endoscopist's number of colonoscopies } \\
(n=15,459)\end{array}$} & $\cdot \mathrm{Q} 1(\leq 57)$ & $198(1.3 \%)$ & $2(1.2 \%)$ & $1.00(-0.38-2.38)$ & \multirow[t]{4}{*}{0.03} \\
\hline & • Q2 (58-278) & $1647(10.8 \%)$ & $18(11.2 \%)$ & $1.08(0.58-1.58)$ & \\
\hline & • Q3 (279-507) & $5340(34.9 \%)$ & 39 (24.2\%) & $0.72(0.50-0.95)$ & \\
\hline & • Q4 (> 507) & $8113(53.0 \%)$ & $102(63.4 \%)$ & $1.24(1.00-1.48)$ & \\
\hline \multirow[t]{2}{*}{ Complexity of hospital $(n=15,707)$} & • Third level & $7150(46.0 \%)$ & $52(32.1 \%)$ & $0.72(0.53-0.92)$ & \multirow[t]{2}{*}{$<0.001$} \\
\hline & - Second level & 8395 (54.0\%) & $110(67.9 \%)$ & $1.29(1.05-1.53)$ & \\
\hline
\end{tabular}

$A D R$ Adenoma detection rate, ASA American Society of Anesthesiologists' Physical Status, CI Confidence interval, $H b$ Hemoglobin, IQR Interquartile range, $P S$ Performance status

${ }^{a}$ Significance in the univariant analysis using the Chi-square test for qualitative variables and the Student's $t$ test for cuantitative variables

1.19), due to colonoscopy complications: $0.02 \%$ (95\% CI 0.00-0.05) due to resection of colorectal lesions: $1.00 \%$ (95\% CI 0.85-1.16). In the seven hospitals taking part in the CRC screening program, the surgery rate ranged across participating hospitals between $0.27 \%$ (95\% CI $0.05-0.50$ ) and $1.89 \%$ (95\% CI 1.36-2.43). After excluding transanal surgeries (31) the colectomy rate was $0.83 \%$ (95\% CI $0.69-0.98$ ). The colectomy rate again ranged between $0.23 \%$ (95\% CI $0.03-0.43$ ) and $1.62 \%$
(95\% CI 1.06-2.17). In Table 1, we outline the characteristics of the sample as well as the surgery rate according to dependent variables and in Supplementary Table 1 we show the same results referred to colectomies.

Seventy-one endoscopists from seven hospitals took part in the first round of the CRC screening program. The median number of colonoscopies performed was 278 (IQR 56-507) and the median ADR was 65.3\% (IQR 60.0-70.08\%). We classified endoscopists into quartiles 
according to number of colonoscopies performed and ADR. Finally, hospitals were classified into tertiary (three) and secondary (four).

\section{Type of surgery and complications}

As we show in Table 2, the main surgical approach was laparoscopy (57.4\%). The most common surgeries performed were right-sided interventions $(51.3 \%)$ and transanal resections (19.1\%). The median length of hospitalization was 6 days with minor and major complications in $n=28$ (17.3\%) and $n=12(7.4 \%)$ patients, respectively. Only one patient died due to surgery. After discharge, complications were detected in $n=29$ (18.1\%) patients, mainly due to intestinal subocclusion (5), rectal bleeding (3), abdominal wall hernia (11), anastomotic stenosis (2) and change in bowel movements (3). After colectomy, intrahospital complications were detected in $n=34$ (26\%) patients, mostly minor $(n=23)$ and complications after discharge in $n=28$ patients (21.4\%). In contrast, inhospital and out-of-hospital complications were detected in six $(19.4 \%)$ and one $(3.2 \%)$ patients after transanal surgery, respectively.

\section{Characteristics of the resected colorectal lesions}

As we show in Table 3, most commonly surgically resected lesions were either right-sided $(49.6 \%)$ or located in the rectum (22.2\%). Median endoscopic size was $35 \mathrm{~mm}$ and most lesions were either sessile, flat or laterally spreading tumors. The lesions had a SMSA score above 12 in most cases (76.7\%). An endoscopic resection was attempted in $23.5 \%$ of patients either in the work-up colonoscopy or in scheduled therapeutic colonoscopy. Median surgical size of the lesion was $25 \mathrm{~mm}$ and, as in the endoscopic histology, the most common histology was adenomatous (81.8\%).

\section{Factors associated with surgery}

During bivariate analysis, several factors related to the patient (age), screening program (FIT result and number of baseline colonoscopies performed), characteristics of the lesions detected (number of polyps and adenomas, adenoma size and classification according to the European guidelines for CRC screening), endoscopist quality metrics (ADR and number of colonoscopies performed), and hospital complexity were significantly associated with the surgery rate as shown in Table 2 . With respect

Table 2 Surgery indications and complications

\begin{tabular}{|c|c|c|}
\hline & & Number (\%) \\
\hline \multirow[t]{2}{*}{ Indication for surgery $(n=162)$} & - Colonoscopy complications & $4(2.5 \%)$ \\
\hline & - Resection of colorectal lesions & $158(97.5 \%)$ \\
\hline \multirow{4}{*}{$\begin{array}{l}\text { Surgical approach } \\
(n=162)\end{array}$} & - Laparoscopy & $84(51.8 \%)$ \\
\hline & - Reconverted laparoscopy & $9(5.5 \%)$ \\
\hline & - Laparotomy & $38(23.1 \%)$ \\
\hline & - Transanal surgery & $31(19.1 \%)$ \\
\hline \multirow{8}{*}{$\begin{array}{l}\text { Type of surgery } \\
(n=162)\end{array}$} & - Expanded appendectomy & $9(5.6 \%)$ \\
\hline & - Right hemicolectomy & $74(45.7 \%)$ \\
\hline & - Left hemicolectomy & $6(3.7 \%)$ \\
\hline & - Sigmoidectomy & $15(9.2 \%)$ \\
\hline & - Rectum anterior resection & $8(4.9 \%)$ \\
\hline & - Segmental resection & $14(8.6 \%)$ \\
\hline & - Subtotal colectomy & $5(3.1 \%)$ \\
\hline & - Transanal surgery & $31(19.1 \%)$ \\
\hline Length of hospitalization $(n=162)$ & & $6(\mathrm{IQR} 4-9)$ \\
\hline \multirow{6}{*}{$\begin{array}{l}\text { In hospital complications }{ }^{a} \\
(n=162)\end{array}$} & $\cdot 0$ & $122(75.3 \%)$ \\
\hline & $\cdot 1$ & $19(11.7 \%)$ \\
\hline & $\cdot \|$ & $9(5.6 \%)$ \\
\hline & $\cdot|| \mid$ & $6(3.7 \%)$ \\
\hline & $\cdot \operatorname{IV}$ & $5(3.1 \%)$ \\
\hline & $\cdot \vee$ & $1(0.6 \%)$ \\
\hline Complications after discharge $(n=160)$ & & $29(18.1 \%)$ \\
\hline
\end{tabular}

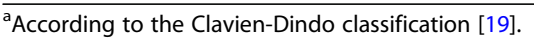


Table 3 Characteristics of colonic lesions resected surgically

\begin{tabular}{|c|c|c|}
\hline & & Number (\%) \\
\hline \multirow[t]{9}{*}{ Location ( $n=158)$} & - Appendix & $10(6.3 \%)$ \\
\hline & - Cecum & $28(17.7 \%)$ \\
\hline & - Ascending colon & $26(16.5 \%)$ \\
\hline & - Hepatic flexure & $14(8.9 \%)$ \\
\hline & - Transverse colon & $13(8.2 \%)$ \\
\hline & - Splenic flexure & $3(1.9 \%)$ \\
\hline & - Descending colon & $9(5.7 \%)$ \\
\hline & - Sigmoid colon & $20(12.7 \%)$ \\
\hline & - Rectum & $35(22.2 \%)$ \\
\hline \multirow[t]{3}{*}{ Endoscopic resection attempt $(n=158)$} & - Surgery directly & $109(68.9 \%)$ \\
\hline & - In baseline colonoscopy & $29(18.4 \%)$ \\
\hline & - In therapeutic colonoscopy & $20(12.7 \%)$ \\
\hline \multirow[t]{4}{*}{ Type of endoscopic resection $(n=153)$} & - No resection & $118(74.7 \%)$ \\
\hline & - Incomplete resection & $32(20.3 \%)$ \\
\hline & - Piecemeal resection & $6(3.8 \%)$ \\
\hline & - En bloc resection & $2(1.3 \%)$ \\
\hline Endoscopic size $(\mathrm{mm})(n=154)$ & & $35(25-50)$ \\
\hline \multirow[t]{5}{*}{ Morphology $(n=155)$} & - Pedunculated & $11(7.0 \%)$ \\
\hline & - Sessile & $70(44.3 \%)$ \\
\hline & - Flat & $17(10.8 \%)$ \\
\hline & - Flat-depressed & $6(3.8 \%)$ \\
\hline & - Laterally spreading tumor & $51(32.3 \%)$ \\
\hline \multirow[t]{8}{*}{ Endoscopic histology $(n=158)$} & - Tubular adenoma with LGD & $26(16.4 \%)$ \\
\hline & - Villous adenoma with LGD & $51(32.2 \%)$ \\
\hline & - Adenoma with HGD & $42(26.5 \%)$ \\
\hline & - Adenoma with intramucosal carcinoma & $6(3.8 \%)$ \\
\hline & - Serrated lesion & $7(4.4 \%)$ \\
\hline & - Serrated lesion with HGD & $1(0.6 \%)$ \\
\hline & - Other histology & $1(0.6 \%)$ \\
\hline & - No biopsy & $24(15.2 \%)$ \\
\hline \multirow[t]{3}{*}{ SMSA classification $(n=150)$} & $\cdot 6-8$ & $4(2.7 \%)$ \\
\hline & $\cdot 9-12$ & $31(20.7 \%)$ \\
\hline & $\cdot>12$ & $115(76.7 \%)$ \\
\hline Surgical size $(\mathrm{mm})(n=136)$ & & $25(20-40)$ \\
\hline \multirow{8}{*}{$\begin{array}{l}\text { Surgical histology } \\
(n=158)\end{array}$} & - No residual lesion & $10(6.3 \%)$ \\
\hline & - Tubular adenoma with LGD & $19(12.0 \%)$ \\
\hline & - Villous adenoma with LGD & $45(28.5 \%)$ \\
\hline & - Adenoma with HGD & $53(33.5 \%)$ \\
\hline & - Adenoma with intramucosal carcinoma & $12(7.8 \%)$ \\
\hline & - Serrated lesion & $9(5.7 \%)$ \\
\hline & - Serrated lesion with HGD & $4(2.5 \%)$ \\
\hline & - Other & $6(3.8 \%)$ \\
\hline
\end{tabular}


to colectomy, we also identified several associated variables as shown in supplementary Table 1 .

Finally, in the multivariable logistic regression analysis we identified several variables independently associated with the risk of surgery: age $\geq 60$ years $(\mathrm{OR}=1.57,95 \%$ CI 1.11-2.23), female sex (OR $=2.10,95 \%$ CI $1.52-2.91)$, the European guidelines classification (high risk $\mathrm{OR}=$ 67.94, 95\% CI 24.87-185.59; intermediate risk OR = 5.63, 95\% CI 1.89-16.80: low risk OR $=1.43$; $95 \%$ CI $0.36-$ 5.75), the endoscopist's ADR (Q4 OR $=0.44,95 \% \mathrm{CI}$ 0.28-0.68; Q3 OR =0.44, 95\% CI 0.27-0.71; Q2 OR = $0.71,95 \%$ CI $0.44-1.14$ ) and a tertiary hospital (OR = 0.54; 95\% CI 0.38-0.79) (Table 4). After excluding transanal surgeries, the same variables were independently related to risk of colectomy: age $\geq 60$ years $(\mathrm{OR}=1.93,95 \%$ CI 1.30-2.89), female sex (OR $=2.21,95 \%$ CI 1.54-3.16), the European guidelines classification (high risk OR = 53.21, 95\% CI 19.36-146.18; intermediate risk OR $=5.33$, 95\% CI 1.77-16.03; low risk OR $=1.07$; 95\% CI $0.24-$ 4.78), the endoscopist's $\mathrm{ADR}(\mathrm{Q} 4 \mathrm{OR}=0.37,95 \% \mathrm{CI}$ 0.23-0.61; Q3 OR=0.48, 95\% CI 0.29-0.79; Q2 OR= $0.58,95 \% \mathrm{CI} 0.34-1.00)$ and a tertiary hospital $(\mathrm{OR}=$ 0.57 ; $95 \%$ CI $0.38-0.85)$.

\section{Discussion}

Our study reports the surgery rate in patients with nonmalignant lesions detected within a mass CRC screening program and the factors related to it. Most surgeries are related to resection of colorectal lesions and, exceptionally, to endoscopic complications. This information is extremely relevant to measure overtreatment risks in this setting. Fortunately, the surgery rate is low and the associated risk of mortality is as expected: one related death in 15,000 subjects. However, we have determined that not only factors associated with the patient and endoscopic findings but also the endoscopist's performance measured with the ADR and hospital level of complexity are independently associated with surgery rate.

Our study has several strengths. The first is related to its population-based perspective. We have collected data from the first round of the Galician CRC screening program. During this initial round, FIT was offered to 721,349 subjects aged 50-69 years, colonoscopies were performed in seven hospitals and quality indicators of seventy-one endoscopists were collected in a centralized database. This database enabled us to calculate surgery rate according to the different variables available. Thus, we could accurately determine the risk of overtreatment in a mass screening program and the side effects related to surgery. There is not much information available to compare our data. As an example, in a retrospective study performed within the scope of the national English Bowel Cancer Screening Program, surgery rate in large polyps ( $\geq 20 \mathrm{~mm}$ flat or sessile) attained $21.7 \%$ [22]. Our data are not comparable because the European guidelines high risk group includes adenomas of any morphology $\geq 20 \mathrm{~mm}$ in size and/or $\geq 5$ adenomas. In fact, most surgically resected lesions in our study were either sessile, flat or laterally spreading tumors (93\%) with a SMSA $>12$ in most cases. A French study evaluated the frequency and risk factors for the surgical resection of non-malignant polyps detected in a FIT based mass CRC screening program [12]. In this study, the surgery rate in patients with any polyp detected was $4.1 \%$ and

Table 4 Factors independently associated with colorectal surgery and colectomy in the logistic regression analysis

\begin{tabular}{|c|c|c|c|}
\hline & & $\begin{array}{l}\text { Colorectal surgery }(n=162) \\
\text { Odds Ratio }(95 \% \mathrm{Cl})^{\mathrm{a}}\end{array}$ & $\begin{array}{l}\text { Colectomy }(n=131) \\
\text { Odds Ratio }(95 \% \mathrm{Cl})^{\mathrm{a}}\end{array}$ \\
\hline \multirow[t]{2}{*}{$\operatorname{Sex}(n=15,707)$} & - Male & 1 & 1 \\
\hline & • Female & $2.10(1.52-2.91)$ & $2.21(1.54-3.16)$ \\
\hline \multirow[t]{2}{*}{ Age $(n=15,707)$} & $\cdot<60$ years & 1 & 1 \\
\hline & $\cdot \geq 60$ years & $1.57(1.11-2.23)$ & $1.93(1.30-2.89)$ \\
\hline \multirow[t]{4}{*}{ European guidelines classification $(n=15,707)$} & - No adenoma & 1 & 1 \\
\hline & - Low risk & $1.43(0.36-5.75)$ & $1.07(0.24-4.78)$ \\
\hline & - Intermediate risk & $5.63(1.89-16.80)$ & $5.33(1.77-16.03)$ \\
\hline & • High risk & $67.94(24.87-185.59)$ & $53.21(19.36-146.18)$ \\
\hline \multirow[t]{4}{*}{ Endoscopist's ADR $(n=15,459)$} & $\cdot$ - Q1 ( $\leq 60 \%)$ & 1 & 1 \\
\hline & • Q2 (60-65.3\%) & $0.71(0.44-1.14)$ & $0.58(0.34-1.00)$ \\
\hline & • Q3 (65.3-70.8\%) & $0.44(0.27-0.71)$ & $0.48(0.29-0.79)$ \\
\hline & • Q4 (> 70.8\%) & $0.44(0.28-0.68)$ & $0.37(0.23-0.61)$ \\
\hline \multirow[t]{2}{*}{ Complexity of hospital $(n=15,707)$} & • Second level & 1 & 1 \\
\hline & • Third level & $0.54(0.38-0.79)$ & $0.57(0.38-0.85)$ \\
\hline
\end{tabular}


was related with factors related to the size, location, histology, endoscopy center and the endoscopist. In our study, the surgery rate in the patients with at least one adenoma was clearly lower.

We have detected an association between the ADR and the surgery rate independent from the endoscopic findings. ADR is the endoscopist's main quality indicator and has been associated with the risk of interval CRC [23], CRC death [24], detection of serrated polyps [25] and the adenoma detection during surveillance [26]. Although ADR is considered a surrogate for meticulous inspection of the colorectal mucosa, correlation with other important outcomes has never been found. In our case, we hypothesize that our findings reflect an association between the assessment of the mucosa and the endoscopists' resection skills. Out results confirm that endoscopists are a risk factor for surgery in patients with polyps detected in a screening program [12]. Nevertheless, we must draw attention to the high ADR of the endoscopists taking part in the Galician screening program. Although an ADR above $45 \%$ is recommended in a FITbased screening programs [27], in our case $75 \%$ of endoscopists attained a 60\% ADR.

Our study has several limitations related to quality of the data collected in the CRC screening database. First, we used the CMBD to identify all the colorectal surgeries. Although we do not have information regarding the accuracy of the data obtained from the Spanish CMBD, an evaluation of the ICD-9-CM for CRC in an Italian administrative database showed a sensitivity ranging between 98 and 99\% [28]. Unfortunately, information regarding location, morphology of the most advanced lesion, SMSA classification or the visual predicted histology of the lesions detected was not stored. We cannot provide information regarding on the visual suspicion of malignancy of the polyp that could explain some of the referrals to surgery. Additionally this information could explain one of the most striking findings of our study. Although males have an increased risk of advanced neoplasia detection in CRC screening [29] and account for $75 \%$ of the high risk lesions detected [30], in our study, females have an increased risk of surgery. The reason is unclear and we suggest it may be related to differences in the natural history of CRC. There is evidence that the serrated carcinogenic pathway, through hypermethylation and BRAF V600E mutation, with flat or sessile serrated lesions located proximally [31, 32], is more common among females and this could explain our findings. In fact, as the study by Le Roy et al. [12] shows, location is a risk factor for surgery in polyps detected in a screening program. Unfortunately, this information was unavailable for patients not requiring surgery.

Colorectal complications and mortality in our study are within the ranges expected. Data analyzed from a
National Surgical Quality Improvement Program from 2011 to 2014, including 12,732 patients who underwent elective surgery for nonmalignant colorectal lesions, revealed a $0.7 \%$ 30-day mortality rate and $14 \%$ risk of major postoperative adverse events [10]. We also analyzed the long term complications that mainly impair the subject's quality of life [33]. In contrast, endoscopic resection is more cost-effective, has few side effects, complications no greater than 1 to $2 \%$ and mortality below 1/10,000 [2]. In large colorectal lesions, endoscopic resection-related mortality ranges between 0 and $0.08 \%[34,35]$. Despite professional society guidelines and recommendations $[9,36]$, colectomies for benign colon lesions have increased in the last few years. In the US, surgery incidence for nonmalignant lesions has increased from 5.9/100,000 to $9.4 / 100,000$ adults in 2000 and 2014, respectively [10].

Our study highlights the need for improved endoscopic resection techniques. First, endoscopists need to be trained specifically in visual assessment of colorectal lesions and in resection techniques and their results should be continuously monitored. In this sense, we require contrasted quality indicators adapted to each screening scenario (FIT, colonoscopy). Quality indicators such as visual diagnostic yield, complete resection, complications, relapse and colectomy rates in large colorectal polyps should be monitored both per endoscopist and per endoscopy unit. However, complex endoscopic resection techniques such as submucosal dissection and endoscopic full thickness resection should be available and patients should be referred to centralized units where these techniques are performed on a regular basis [36].

\section{Conclusions}

To conclude, the surgery rate in patients with nonmalignant lesions detected in a mass screening program is low and mainly associated with treatment of unresectable polyps. Although complications related to surgery are acceptable, this is an area both endoscopists and endoscopy units can improve upon. In order to reduce the number of subjects referred to surgery, we need to improve the endoscopist resection skills and centralized units for complex techniques should be available. Finally, we require endoscopic resection quality indicators that enable us to continuously monitor endoscopic resection results.

\section{Abbreviations}

ADR: Adenoma detection rate; AJCC: American Joint Committee on Cancer; ASA: American Society of Anesthesiologists' Physical Status; Cl: Confidence interval; CRC: Colorectal cancer; FIT: Fecal immunochemical test;

Hb: Hemoglobin; HGD: High grade dysplasia; IQR: Interquartile range; LGD: Low grade dysplasia; OR: Odds ratio; PS: Performance status; SMSA: Size, Morphology, Site and Access 


\section{Supplementary Information}

The online version contains supplementary material available at https://doi. org/10.1186/s12885-021-08606-w.

Additional file 1: Supplementary Table 1. Baseline characteristics and colectomy rate according to dependent variables.

\section{Acknowledgments}

We thank the administrative staff of the Galician CRC screening program, Rebeca Vázquez Cobelas, María Elvira García Fernández, Jose Francisco Rodríguez García and Leonor García Garrán, for their contribution. We would like to take into consideration the collaboration of all Galician Public Health Service general practitioners, Servizo Galego de Saude. Finally, the Galician CRC screening program would not be possible without the participation of the Clinical Analysis departments and the Endoscopy Units of the seven hospitals of the Servizo Galego de Saude.

\section{Authors' contributions}

The authors' contributions were as follows: JC, AG, RA, ERC, IPRL and RZ participated in the study design and search for financial support; AG, RA, ERC, took part in operation of the CRC screening database; JC and AG participated in design of the study database; $J \mathbf{C}$, took part in the clinical records search; JC performed the statistical analysis and wrote the first draft. Finally, all the authors made comments on the article and approved the submitted version of the manuscript. All authors had full access to all the data (including statistical reports and tables) in the study and can take responsibility for the integrity of the data and accuracy of the data analysis. $J C$ had full access to all of the data in the study and takes responsibility for the integrity of the data and accuracy of the data analysis. JC acts as guarantor of the article. The author(s) read and approved the final manuscript.

Additional contributors: Franco Baiocchi, Coral Tejido Sandoval, Cristina Sánchez Gómez, Natalia de Vicente Bielza.

\section{Funding}

This study was supported by grants from Academia Médico Quirúrgica of Ourense, Spain and the Instituto de Salud Carlos III through project PI17/ 00837 (Co-funded by European Regional Development Fund/European Social Fund "A way to make Europe"/"Investing in your future"). Ciberehd is funded by Instituto de Salud Carlos III. The funders had no role in the content of the manuscript nor in the decision to publish it

\section{Availability of data and materials}

The datasets used and/or analysed during the current study are available from the corresponding author on reasonable request.

\section{Declarations}

\section{Ethics approval and consent to participate}

The local Institutional Review Board of Pontevedra-Vigo-Ourense, Spain assessed and approved the study (code 2018/593). As long as the study was based on database operation, no informed consent was required. The information was accessed according to prevailing European and Spanish legislation.

\section{Consent for publication}

Not required.

\section{Competing interests}

The authors have no conflict of interest to declare. Joaquín Cubiella has financial support from Instituto de Salud Carlos III but has no financial relationships with any organizations that might have an interest in work submitted in the previous five years, and no other relationships or activities that could appear to have influenced the submitted work.

\section{Author details}

'Department of Gastroenterology, Hospital Universitario de Ourense, Rúa Ramón Puga 52-56, 32003 Ourense, Spain. ${ }^{2}$ Instituto de Investigación Sanitaria Galicia Sur, Ourense, Spain. ${ }^{3}$ Centro de Investigación Biomédica en Red Enfermedades Hepáticas y Digestivas, Ourense, Spain. ${ }^{4}$ Department of
Preventive Medicine, Hospital Universitario de Ourense, Ourense, Spain. ${ }^{5}$ Dirección Xeral de Saúde Pública, Conselleria de Sanidade, Santiago de Compostela, Spain.

Received: 22 October 2020 Accepted: 16 July 2021

Published online: 29 July 2021

\section{References}

1. Cancer Today. International Agency for Research on Cancer [https://gco.iarc fr/today/home]. Accessed 21 July 2021.

2. Cubiella J, Marzo-Castillejo M, Mascort-Roca JJ, Amador-Romero FJ, BellasBeceiro B, Clofent-Vilaplana J, et al. Clinical practice guideline. Diagnosis and prevention of colorectal cancer. 2018 Update. Gastroenterol Hepatol. 2018; 41:585-96.

3. Zorzi M, Fedeli U, Schievano E, Bovo E, Guzzinati S, Baracco S, et al. Impact on colorectal cancer mortality of screening programmes based on the faecal immunochemical test. Gut. 2015;64(5):784-90. https://doi.org/10.1136/ gutjnl-2014-307508

4. Levin TR, Corley DA, Jensen CD, Schottinger JE, Quinn VP, Zauber AG, et al. Effects of Organized Colorectal Cancer Screening on Cancer Incidence and Mortality in a Large Community-Based Population. Gastroenterology. 2018; 155:1383-1391.e5.

5. Criteria for appraising the viability, effectiveness and appropriateness of a screening programme Updated 23 October 2015 [https://www.gov.uk/ government/publications/evidence-review-criteria-national-screening-progra mmes/criteria-for-appraising-the-viability-effectiveness-and-appropriatenessof-a-screening-programme]. Accessed 21 July 2021.

6. Vermeer NCA, Snijders HS, Holman FA, Liefers GJ, Bastiaannet E, van de Velde CJH, et al. Colorectal cancer screening: systematic review of screenrelated morbidity and mortality. Cancer Treat Rev. 2017;54:87-98. https://doi. org/10.1016/j.ctrv.2017.02.002.

7. Kalager M, Wieszczy P, Lansdorp-Vogelaar I, Corley DA, Bretthauer M, Kaminski MF. Overdiagnosis in colorectal Cancer screening: time to acknowledge a blind spot. Gastroenterology. 2018;155(3):592-5. https://doi. org/10.1053/j.gastro.2018.07.037.

8. Zauber AG, Winawer SJ, O'Brien MJ, Lansdorp-Vogelaar I, van Ballegooijen $\mathrm{M}$, Hankey BF, et al. Colonoscopic polypectomy and long-term prevention of colorectal-cancer deaths. N Engl J Med. 2012;366(8):687-96. https://doi. org/10.1056/NEJMoa1100370.

9. Ferlitsch M, Moss A, Hassan C, Bhandari P, Dumonceau J-M, Paspatis G, et al. Colorectal polypectomy and endoscopic mucosal resection (EMR): European Society of Gastrointestinal Endoscopy (ESGE) clinical guideline. Endoscopy. 2017;49(3):270-97. https://doi.org/10.1055/s-0043-102569.

10. Peery AF, Cools KS, Strassle PD, McGill SK, Crockett SD, Barker A, et al. Increasing Rates of Surgery for Patients With Nonmalignant Colorecta Polyps in the United States. Gastroenterology. 2018;154:1352-1360.e3.

11. Ma C, Teriaky A, Sheh S, Forbes N, Heitman SJ, Jue TL, et al. Morbidity and mortality after surgery for nonmalignant colorectal polyps: a 10-year Nationwide analysis. Am J Gastroenterol. 2019;114(11):1802-10. https://doi. org/10.14309/ajg.0000000000000407.

12. Le Roy F, Manfredi S, Hamonic S, Piette C, Bouguen G, Riou F, et al. Frequency of and risk factors for the surgical resection of nonmalignant colorectal polyps: a population-based study. Endoscopy. 2016;48(3):263-70. https://doi.org/10.1055/s-0034-1392976.

13. Cubiella J, González A, Almazán R, Rodríquez-Camacho E, Fontenla Rodiles J, Domínguez Ferreiro C, et al. pT1 colorectal Cancer detected in a colorectal Cancer mass screening program: treatment and factors associated with residual and Extraluminal disease. Cancers. 12(9):2530. https://doi.org/10.33 90/cancers 12092530

14. European Colorectal Cancer Screening Guidelines Working G, von Karsa L, Patnick J, Segnan N, Atkin W, Halloran S, et al. European guidelines for quality assurance in colorectal cancer screening and diagnosis: overview and introduction to the full supplement publication. Endoscopy. 2013;45: $51-9$

15. Edge SB, Byrd DR, Compton CC, Fritz AG, Greene FL, Trotti A. AJCC Cancer Staging Manual. 7th ed. New York: Springer-Verlag; 2010.

16. Jover R, Herráiz M, Alarcón O, Brullet E, Bujanda L, Bustamante M, et al. Clinical practice guidelines: quality of colonoscopy in colorectal cancer screening. Endoscopy. 2012;44:444-51.

17. Atkin WS, Valori R, Kuipers EJ, Hoff G, Senore C, Segnan N et al. European guidelines for quality assurance in colorectal cancer screening and 
diagnosis. First Edition--Colonoscopic surveillance following adenoma removal. Endoscopy. 2012;44(Suppl 3):SE151-63.

18. Ministerio de Sanidad, Servicios Sociales e Igualdad [internet]. Hospital discharge records in the national health system. CMBD. [http://www.msssi. gob.es/en/estadEstudios/estadisticas/cmbdhome.htm]. Accessed 21 July 2021.

19. Clavien PA, Barkun J, De Oliveira ML, Vauthey JN, Dindo D, Schulick RD, et al. The clavien-dindo classification of surgical complications: five-year experience. Ann Surg. 2009;250(2):187-96. https://doi.org/10.1097/SLA.0b013 e3181b13ca2.

20. Lambert R, Lightdale CJ. The Paris endoscopic classification of superficial neoplastic lesions: Esophagus, stomach, and colon - Paris, France November 30 to December 1, 2002. Gastrointest Endosc. 2003: 58(6 SUPPL):S3-43.

21. Sidhu M, Tate DJ, Desomer L, Brown G, Hourigan LF, Lee EYT, et al. The size, morphology, site, and access score predicts critical outcomes of endoscopic mucosal resection in the colon. Endoscopy. 2018;50(7):684-92. https://doi. org/10.1055/s-0043-124081

22. Lee TJW, Rees CJ, Nickerson C, Stebbing J, Abercrombie JF, McNally RJQ et al. Management of complex colonic polyps in the English bowel Cancer screening Programme. Br J Surg. 2013;100(12):1633-9. https://doi.org/10.1 002/bjs.9282.

23. Kaminski MF, Regula J, Kraszewska E, Polkowski M, Wojciechowska U, Didkowska J, et al. Quality indicators for colonoscopy and the risk of interval cancer. N Engl J Med. 2010;362(19):1795-803. https://doi.org/10.1056/ NEJMoa0907667.

24. Corley DA, Jensen CD, Marks AR, Zhao WK, Lee JK, Doubeni CA, et al. Adenoma detection rate and risk of colorectal cancer and death. N Engl J Med. 2014;370(14):1298-306. https://doi.org/10.1056/NEJMoa1309086.

25. Zorzi M, Senore C, Da Re F, Barca A, Bonelli LA, Cannizzaro R, et al. Detection rate and predictive factors of sessile serrated polyps in an organised colorectal cancer screening programme with immunochemical faecal occult blood test: the EQuIPE study (evaluating quality indicators of the performance of endoscopy). Gut. 2017;66(7):1233-40. https://doi.org/1 0.1136/gutjnl-2015-310587.

26. Mangas-Sanjuan C, Zapater P, Cubiella J, Murcia Ó, Bujanda L, Hernández V, et al. Importance of endoscopist quality metrics for findings at surveillance colonoscopy: the detection-surveillance paradox. United Eur Gastroenterol J. 2018;6(4):622-9. https://doi.org/10.1177/2050640617745458.

27. Cubiella J, Castells A, Andreu M, Bujanda L, Carballo F, Jover R, et al. Correlation between adenoma detection rate in colonoscopy- and fecal immunochemical testing-based colorectal cancer screening programs. United Eur Gastroenterol J. 2017;5(2):255-60. https://doi.org/10.1177/205064 0616660662.

28. Cozzolino F, Bidoli E, Abraha I, Fusco M, Giovannini G, Casucci P, et al. Accuracy of colorectal cancer ICD-9-CM codes in Italian administrative healthcare databases: a cross-sectional diagnostic study. BMJ Open. 2018; 8(7):e020630. https://doi.org/10.1136/bmjopen-2017-020630.

29. Cubiella J, Castro I, Hernandez V, González-Mao C, Rivera C, Iglesias F, et al. Diagnostic accuracy of fecal immunochemical test in average- and familialrisk colorectal cancer screening. United Eur Gastroenterol J. 2014;2(6):522-9. https://doi.org/10.1177/2050640614553285.

30. Cubiella J, Carballo F, Portillo I, Cruzado Quevedo J, Salas D, Binefa G, et al. Incidence of advanced neoplasia during surveillance in high- and intermediate-risk groups of the European colorectal cancer screening guidelines. Endoscopy. 2016;48(11):995-1002. https://doi.org/10.1055/s0042-112571.

31. Chacko L, Macaron C, Burke CA. Colorectal Cancer screening and prevention in women. Dig Dis Sci. 2015;60(3):698-710. https://doi.org/10.1 007/s10620-014-3452-4.

32. McCashland TM, Brand R, Lyden E, Garmo P. Gender differences in colorectal polyps and tumors. Am J Gastroenterol. 2001;96(3):882-6. https:// doi.org/10.1111/j.1572-0241.2001.03638.x.

33. Giglia MD, Stein SL. Overlooked long-term complications of colorectal surgery. Clin Colon Rectal Surg. 2019;32(3):204-11. https://doi.org/10.1055/s0038-1677027.

34. Ahlenstiel G, Hourigan LF, Brown G, Zanati S, Williams SJ, Singh R, et al. Actual endoscopic versus predicted surgical mortality for treatment of advanced mucosal neoplasia of the colon. Gastrointest Endosc. 2014;80(4): 668-76. https://doi.org/10.1016/j.gie.2014.04.015.
35. Hassan C, Repici A, Sharma P, Correale L, Zullo A, Bretthauer M, et al. Efficacy and safety of endoscopic resection of large colorectal polyps: a systematic review and meta-analysis. Gut. 2016;65(5):806-20. https://doi. org/10.1136/gutjnl-2014-308481.

36. Kaltenbach T, Anderson JC, Burke CA, Dominitz JA, Gupta S, Lieberman D, et al. Endoscopic removal of colorectal lesions-recommendations by the US multi-society task force on colorectal Cancer. Gastroenterology. 2020; 158(4):1095-129. https://doi.org/10.1053/j.gastro.2019.12.018.

\section{Publisher's Note}

Springer Nature remains neutral with regard to jurisdictional claims in published maps and institutional affiliations.
Ready to submit your research? Choose BMC and benefit from:

- fast, convenient online submission

- thorough peer review by experienced researchers in your field

- rapid publication on acceptance

- support for research data, including large and complex data types

- gold Open Access which fosters wider collaboration and increased citations

- maximum visibility for your research: over $100 \mathrm{M}$ website views per year

At BMC, research is always in progress.

Learn more biomedcentral.com/submissions 